\title{
Pleomorphic Adenoma of the Palate with Specific Management: A Case Presentation
}

\author{
Kwedi K G G ${ }^{1 *}$, Diatta $\mathrm{M}^{2,3}$, Diakité $\mathrm{Y}^{1}$, Tamba B ${ }^{2,3}$, Niang $\mathrm{Sm}^{3}$, Kebe $\mathrm{NF}^{3}$, Dia Tine $\mathrm{S}^{2,3}$ \\ ${ }^{1}$ Specialized Degree of Oral Surgery, Institute of Odontology and Stomatology, University Cheikh Anta Diop, Dakar, Senegal \\ ${ }^{2}$ Oral Surgery Service, Institute of Odontology and Stomatology, University Cheikh Anta Diop, Dakar, Senegal \\ ${ }^{3}$ Odontostomatology Department of Idrissa Pouye General Hospital, Dakar, Senegal
}

\author{
Article History \\ Received: 24.08 .2020 \\ Accepted: 10.09 .2020 \\ Published: 30.10 .2020
}

Journal homepage:

https://www.easpublisher.com/easjdom

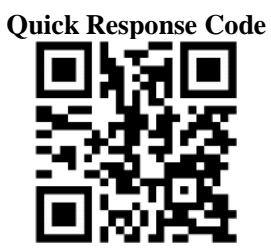

Abstract: Introduction: Pleomorphic adenoma is a benign neoplasm that develop at the expense of the salivary gland. It evolves without symptoms; the reason why late consultations are often observed. The size of its volume can have an important functional implication. Observation: A 22 years old patient was referred by a dental surgeon for a palatal swelling evolving for two years. Intraoral examination presented an ovoid palatal mass not crossing the median line. It was covered with normal mucosal. The swelling on palpation was non tender and with a firm consistency. The scanner presented a well limited homogenous lesion located at the palate. Excision was done under general anaesthesia. Palatal silicone plate was used to protect the operated wounds. Post operation evolution was simple. Discussion: Pleomorphic adenoma is one of the most frequents benign salivary glands tumours. It is relatively rare intraorally, but when it occurs it is mostly located at the palate. It is recommended to use a palatal plate after surgery to facilitate healing and promote oral functions like phonation, as well as feeding. However, most often we are faced with unforeseen events that do not permit us to follow the usual pattern. Conclusion: Oral surgeon must be able to adapt to any situation in order to provide quality services regardless of the context.

Keywords: Pleomorphic adenoma; palate; palatal plate; management.

Copyright ( $) 2020$ The Author(s): This is an open-access article distributed under the terms of the Creative Commons Attribution 4.0 International License (CC BY-NC 4.0) which permits unrestricted use, distribution, and reproduction in any medium for non-commercial use provided the original author and source are credited.

\section{INTRODUCTION}

Pleomorphic adenoma is a benign mixed tumour of the salivary glands with variable encapsulation. It develops preferentially at the level of the main salivary glands [1]. Pleomorphic adenoma is less frequent in the oral cavity, mostly located at the palate and develops at the expense of accessory salivary glands disseminated within the oral mucosa [2]. Pleomorphic adenoma is a major concern for the oral surgeon because of its risk of malignant degeneration and due to possible functional disorders when located in the palate. It evolves without symptoms, which explains the late consultation often observed. The reported case is that of a 22-year-old female patient referred by her dentist for palatal swelling that had evolved for two years.

\section{OBSERVATION}

A 22 years old female patient referred to the odonto-stomatology department of le Grand Yoff General Hospital by her attending dentist for palatal swelling over the past two years, associated with phonation and swallowing impairments.
The patient had no particular medical or surgical history. Extra oral examination showed facial symmetry and the presence of non-tender movable bilateral submandibular lymphadenopathy.

The intraoral examination revealed an ovoid mass, about $5.5 \mathrm{~cm}$ along its major axis, ranging from tooth number 13 to tooth number 17 , covered with a healthy-looking mucous membrane of firm consistency, painless and not associated with the bone.

It was located at the right anterior region of the hard palate, not extending beyond the median raphe.

On palpation it had a firm consistency, nontender and mobile in relation to the deep plane (Figure1).

Her oral hygiene was poor with the presence of dental calculus and mobility of tooth number 16. Based on the history and physical examination, a presumptive diagnosis of pleomorphic adenoma of the accessory salivary glands of the palate was made. Odontogenic cyst was our differential. Additional examinations were requested. Orthopantomogram was not contributory. 
Computed tomography revealed a homogeneous lesion in the palate, approximately $5.5 \times 3.5 \mathrm{~cm}$, with well limited edges and strongly enhanced with contrast medium.

It presented rounded contours and a mass effect on the palate (Figure-2). The patient was sent for a pre-anesthetic consultation and excision of the lesion was scheduled under general anesthesia.

The patient was operated by palatal approach. Intrasulcular incision extending from tooth number 12 to tooth number 17 , then a median rectilinear superficial incision of approximately $5 \mathrm{~cm}$ was made, followed by a step by step dissection (Figure-3). Complete excision of the tumor was as conservative as possible, avulsion of tooth number 16 and alveolar curettage (Figure-4). Simple interrupting stitches were done. Fabrication of resin based palatal plate was not possible. A silicone based palatal plate was made (Figure-5).

Histological examination showed a benign tumor surrounded by a fibrous capsule with two types of cells; one epithelial and the other myxoid connective tissues type with zones of cartilaginous differentiation. Pleomorphic adenoma was the histopathological diagnosis.

There was no post-op complication observed. Follow ups were done on d7, d14, d30, d30 and d120 during which the palatal plate was removed to check on the evolution of the operated site. The plate was readjusted whenever there was need. There was complete healing of the palate by d180 (Figure-7).

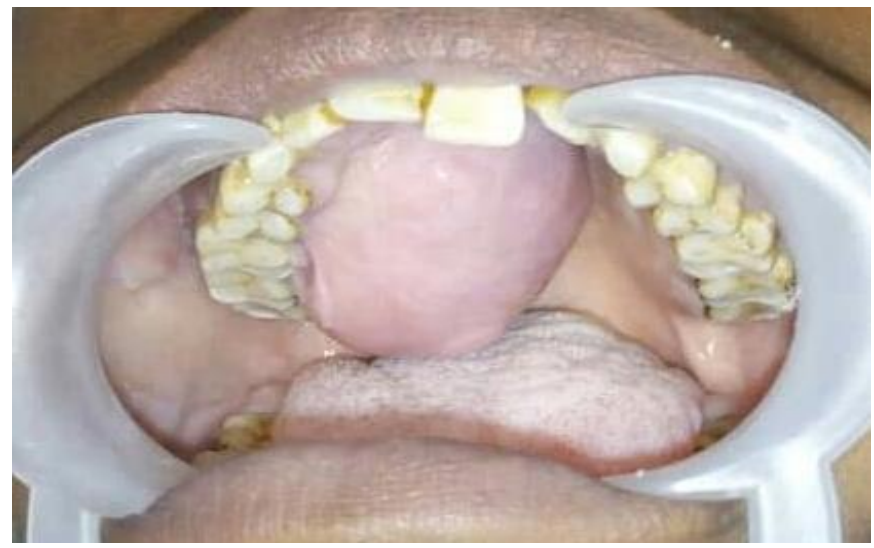

Fig-1: Intraoral view of the palatal mass of pleomorphic adenoma

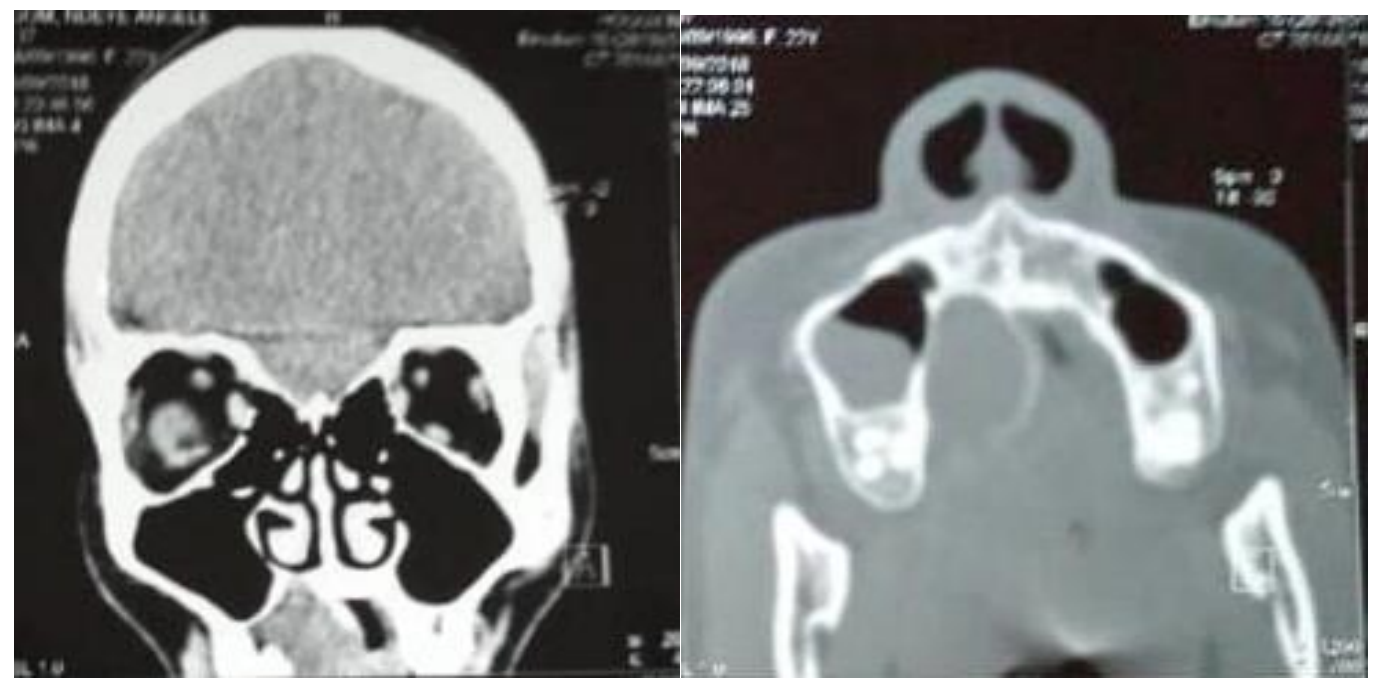

Fig-2: CT Scan of the palatal mass 


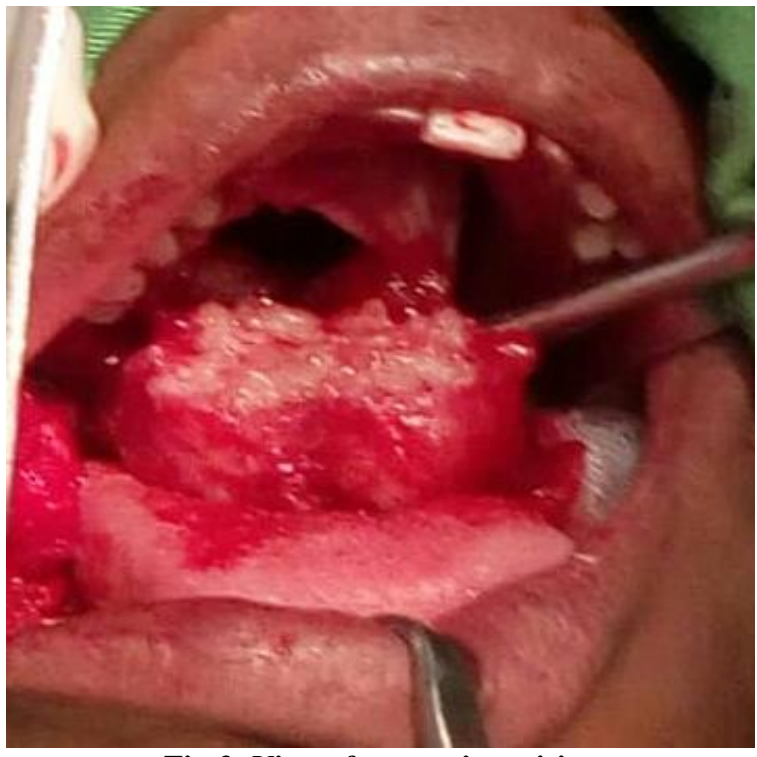

Fig-3: View of tumour's excision

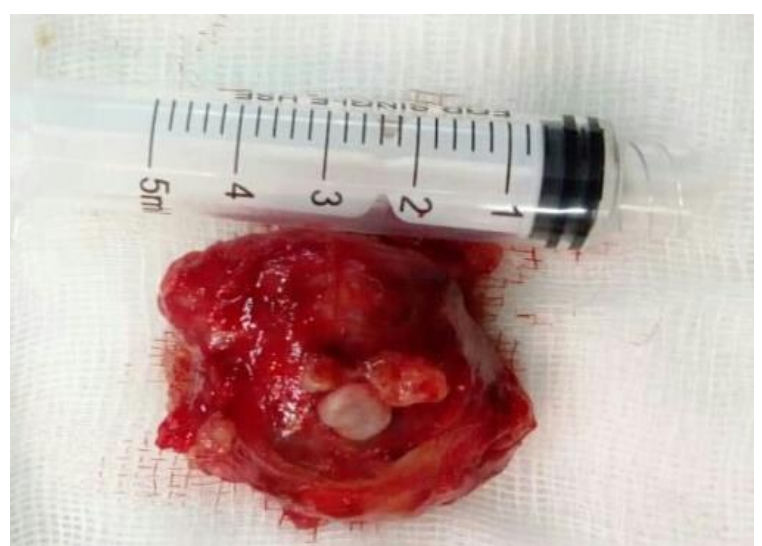

Fig-4: View of excised mass

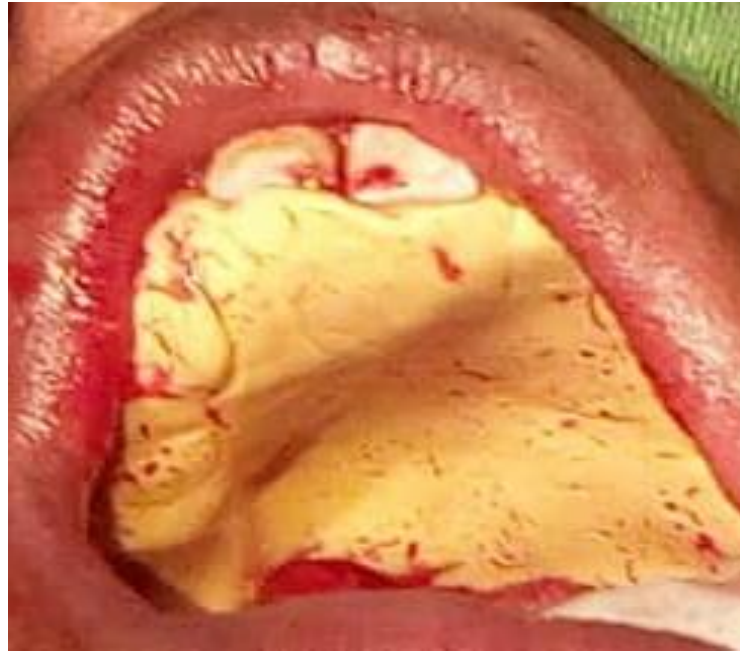

Fig-5: View of silicone palatal plate

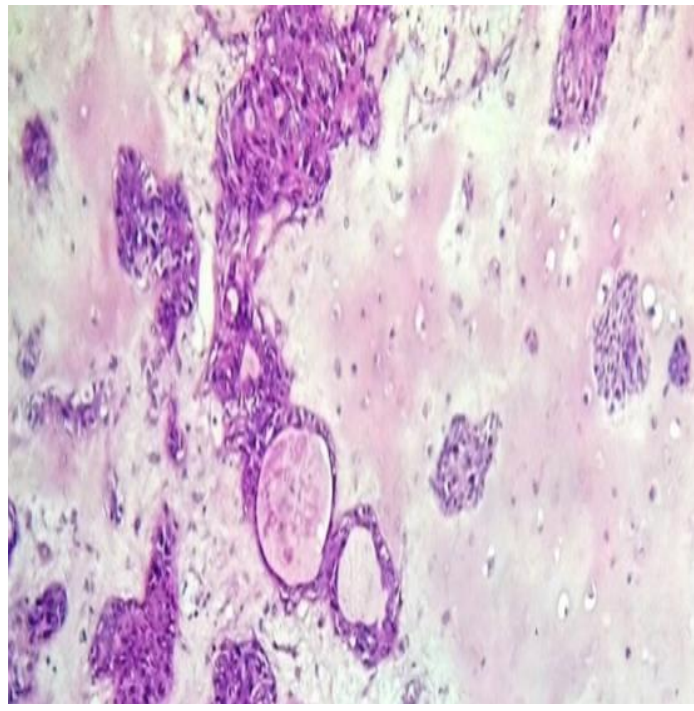

Fig-6: Histological view of pleomorphic adenoma

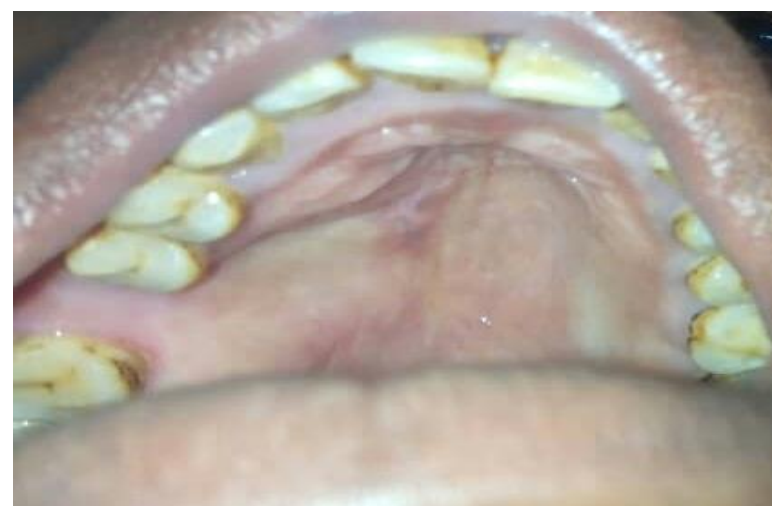

Fig-7: Intraoral view of the palate three months after surgery

\section{DISCUSSION}

Pleomorphic adenoma is one of the most frequent salivary gland tumors. It represents about $60 \%$ of benign tumors of the salivary glands [3,4]. This tumor is rarely located intraorally, just about $4-5 \%$ involve the accessory salivary glands with predilection at the palate [5]. It is mostly observed in people with the age group that varies between 30 -40 years and the female gender [6]. The patient was 22 years in our case. However, some studies have reported cases of pleomorphic adenoma with even younger age, Dhanuthai et al was the first to report a patient of age 13 years with pleomorphic adenoma [7].

Pleomorphic adenoma is often presented as a slowly growing, painless tumor. Intraorally, they are often found at the junction between the hard and soft palates. It usually appears as a round or ovoid mass, of firm consistency, mobile in relation to the deep plane, one-sided and covered with a healthy-looking mucous membrane. These lesions are usually between $1-2 \mathrm{~cm}$ in diameter [5, 8]. In our case, the mass was about $5.5 \times 3.5 \mathrm{~cm}$. 
Many infectious and neoplasm pathologies can be found in the palate, making the diagnosis difficult. In our case, the odontogenic cyst of the jawbones was cited as the differential. According to some authors, malignant tumors such as muco-epidermoid carcinoma, polymorphic adenocarcinoma or cystic adenoid carcinoma which is also the main malignant tumor of the accessory salivary glands, and mainly located in the palate should be taken into account $[9,10]$.

In view of the multitude of possible diagnoses, it is imperative to complete the examination with radiological and histological explorations. In our case, orthopantomogram, computed tomography and histological workups were used.

Surgical excision is the treatment of choice for pleomorphic adenoma [11]. The excision must be complete in order to avoid recurrence. Although rare, the risk of malignant transformation of pleomorphic adenoma after recurrence is very high.

The palatal plate or healing guide is a device used after surgery at the palate. It is made preoperatively after taking an impression and placed after surgery. It is usually made of acrylic resin or thermoformed plastic. The use of the palatal plate after surgery on the palate facilitates healing, restores certain functions such as speech or nutrition and thus improves the patient's living conditions [12]. In our case, heavybased silicone impression material was used as the palatal plate due to absence of a conventional plate and we obtained similar results. The silicone material has the advantage of being less expensive for the patient. It is placed directly in the mouth after surgery, which reduces the risk of device failure seen with conventional plates. A failure often due to uncontrolled anatomical changes during the operation, the consequences of which can only be assessed after the surgery.

\section{Conclusion}

The use of a palatal plate improves the living conditions of patients who have had surgery on the palate. Maintaining oral functions such as phonation and nutrition should always be taken into account in the management of this type of case. The oral surgeon must stay apt with his ability to adapt to any situation in order to provide quality services regardless of the context.

\section{REFERENCES}

1. Ansari, M. H. (2007). Salivary gland tumors in an Iranian population: a retrospective study of 130 cases.Journal of oral and maxillofacial surgery, 65(11), 2187-2194.

2. Dalgic, A., Karakoc, O., Aydin, U., Hidir, Y., Gamsizkan, M., \& Karahatay, S. (2014). Minor gland neoplasm. J Craniofac Surg. 25:289-91.

3. Spiro, R. H. (1986). Salivary neoplasms: overview of a 35-year experience with 2,807 patients. Head Neck Surg. 8:177-184.

4. Neville, B. W., Damm, D. D., \& Allen, C. M. (2002). Oral \& maxillofacial pathology. 2nd ed. Phila. PA : Saunders; 337-369.

5. Hmidi, M., Aatifi, H., Boukhari, A., Zalagh, M., \& Messary, A. (2015). Pleomorphic adenoma of the soft palate: major tumor in a minor gland. Pan African Medical Journal, 22(1):281.

6. Hamama, J., Khayati, S., Arrob, A., \& Abouchadi, A. (2015). Adénome pléomorphe des glandes salivaires accessoires. AOS; 271:4-9.

7. Erdem, M. A., Cankaya, A. B., Guven, G., Olgaç, V., \& Kasapoglu, C. (2011). Pleomorphic adenoma of the palate. J Cranio Surg. 22(3):11311134.

8. Chaturvedi, M., Jaidev, A., Thaddanee, R., \& Khilnani, A. (2018). Large pleomorphic adenoma of the hard palate. Ann Maxillofac Surg. (8): 46371.

9. Gauzeran, D. (2011). Pathologies tumorales des glandes salivaires accessoires. Rev Odonto Stomat. 40:53-69.

10. Naji, Y., Alaoui, O. M., \& Yahya, I. B. (2016). Adenocarcinome polymorphe de pas grade du palais mou : revue et rapport de cas. Med Buccale Chir Buccale, 22(2): 131-136.

11. Uz, U., \& Celik, O. (2017). Pleomorphic adenoma of the posterior surface of the soft palate causing sleep disturbance: A case report. The American Journal of Case Reports, 18, 1266.

12. Goiato, M. C., Tamae, A. C., Silva, P. I. S., dos Santos, D. M., Iyda, M. G., Moreno, A., ... \& Bertoz, A. P. M. (2011). Oral rehabilitation after surgical removal of pleomorphic adenoma. Journal of Craniofacial Surgery, 22(6), 1996-1999. 